\title{
Bile Secretion and its Control in the Newborn Puppy
}

\author{
NICOLA TAVOLONI \\ Department of Medicine (Polly Annenberg Levee Hematology Center) and Department of Physiology, Mount \\ Sinai School of Medicine, New York, New York 10029
}

\begin{abstract}
To gain information about the ontogeny of neonatal biliary physiology, we determined gallbladder bile composition, hepatic bile flow and composition, and the choleretic effects of taurocholate, taurodehydrocholate, secretin, and glucagon in anesthetized puppies of 0-3 $n=$ 13), 7-21 $(n=9)$, and 28-42 $(n=8)$ days of age, and in fed $(n=4)$ and fasted $(n=4)$ adult dogs. Although gallbladder bile volume was similar in all puppies, chloride concentration in gallbladder bile declined with age $\mathbf{( 5 4 . 2}$, $33.2,22.6,15.9$, and $5.8 \mathrm{mEq} /$ liter in these respective groups), and so did bicarbonate concentration $(43.5,26.1$, 17.6, 11.4, and $5.7 \mathrm{mEq} /$ liter). In contrast, the concentrations of sodium $(175.4,189.2,224.5,251.6$, and 279.4 $\mathrm{mEq} /$ liter) and bile acids $(77.8,137.3,206.2,219.6$, and $280.7 \mathrm{mEq} / \mathrm{liter}$ ) increased. Spontaneous bile flow rate in 0 - to 3-day-old puppies averaged $0.194 \mu \mathrm{l} / \mathrm{min} / \mathrm{g}$ and increased to $0.365 \mu \mathrm{l} / \mathrm{min} / \mathrm{g}$ in puppies of $28-42$ days of age. The latter value was not significantly different from that in fed adult dogs $(0.344 \mu \mathrm{l} / \mathrm{min} / \mathrm{g}) .{ }^{14} \mathrm{C}$-erythritol bile-toplasma ratio in spontaneously secreted bile increased with age $(1.05,1.08,1.26,1.48$, and 1.70), and chloride concentration decreased $(96.8,85.8,79.2,74.3$, and $60.1 \mathrm{mEq} /$ liter). The choleretic activity of taurocholate $(2 \mu \mathrm{mol} / \mathrm{min} /$ $\mathrm{kg})$ was the same in all puppies $(7.8 \mu \mathrm{l} / \mu \mathrm{mol})$ and adult animals $(7.2 \mu \mathrm{l} / \mu \mathrm{mol})$. Taurodehydrocholate $(2 \mu \mathrm{mol} / \mathrm{min} /$ $\mathrm{kg}$ ) increased bile flow by a greater magnitude, yet its choleretic activity in the puppies $(13.3 \mu \mathrm{l} / \mu \mathrm{mol})$ was the same as that in adult dogs $(12.7 \mu \mathrm{l} / \mu \mathrm{mol})$. In all animals, total bile acid excretion accounted for $70-95 \%$ of the infused taurocholate or taurodehydrocholate. Secretin (1$20 \mathrm{CU} / \mathrm{kg} / \mathrm{h})$ and glucagon $(1-20 \mu \mathrm{g} / \mathrm{kg} / \mathrm{h})$ produced a minimal, or no effect on bile flow in 0- to 3-day-old puppies. In puppies of 28-42 days of age, the choleretic effect of these hormones was $30-45 \%$ of that seen in adult animals. These findings suggest that gallbladder and ductular bile water reabsorption, canalicular secretion, and hormone choleresis are all deficient processes in the newborn puppy and develop during postnatal life. (Pediatr Res 20: 203-
\end{abstract} 208, 1986)

\section{Abbreviations}

TC, taurocholate

TDHC, taurodehydrocholate

$B / P$, bile-to-plasma ratio

Received June 5. 1985; accepted October 10, 1985.

Address all correspondence and reprint requests to Nicola Tavoloni, Ph.D., Division of Hematology, Mount Sinai School of Medicine, Madison Avenue and 100th Street, New York, NY 10029.

This work was supported by Grant HD 17556 from the National Institute of Child Health and Human Development.
Transition from fetal to extrauterine life is often associated with development of new or immature homeostatic mechanisms which are essential for the independent survival of the newly born organism. This is particularly true in the liver, for many of its functions in utero are carried out by the placenta and much of its blood is shunted via the ductus venosus, bypassing the sinusoidal circulation. Considerable evidence has, in fact, accumulated to indicate that a variety of biochemical functions of the hepatocyte are immature at birth, and develop during postnatal life (1). Clinical and experimental observations also suggest that bile formation, a major hepatic function, is immature at birth. Bile acid pool size (2-4), synthesis $(4,5)$, hepatic uptake $(6,7)$, and intestinal absorption $(8-10)$ are all deficient in the newborn organism, and certain cholestatic syndromes strike more often neonates than adult subjects $(11,12)$. Furthermore, studies from our laboratory have demonstrated that the rate of bile flow is significantly reduced in the newborn puppy, and adult levels are not achieved before the 3-5th wk of postnatal life (13).

However, hepatic bile formation involves multiple secretory processes, and present information about the mechanisms operative in the newborn liver is quite inadequate. Accordingly, to gain a deeper insight into the ontogeny of neonatal bile secretory physiology, we studied the secretion and composition of bile in puppies 0-42 days of age, and the role of bile acid and hormone cholereses during such a period of postnatal life.

\section{METHODS}

Animals and drugs. These studies were carried out in anesthetized, bile duct-cannulated mongrel puppies of $0-42$ days of age $(n=30)$ and adult dogs $(n=8)$. The puppies (17 males and 13 females) were obtained from six litters and had free access to suckling during the period of study, although the 0 -h-old puppies were removed from the mother within 15-180 min after delivery. The puppies from each litter were studied at different ages during the 6-wk period, namely: one puppy always at $0 \mathrm{~h}$ after birth; one to three at 1-3 days; one to two at 7 and/or 14 days; and one to two at 21,28 , and/or 42 days after. Experiments were appropriately scheduled so that litter sizes were kept approximately similar to each other during the 42-day period. The puppies' diet was not supplemented, even though by the 5-6th wk of age, they had begun to chew their mother's food. Experiments in adult dogs (six males and two females) were performed either after a 24 -h fasting period $(n=4)$, or three $\mathrm{h}$ after being fed a standard meal $(n=4)$. Adult dogs had free access to water.

${ }^{14} \mathrm{C}$-erythritol $(100 \mathrm{mCi} / \mathrm{mmol})$ was obtained from Amersham, Arlington Heights, IL; pentobarbital sodium from Abbott, King of Prussia, PA; ketamine from Park-Davis, Morris Plains, NJ; TC and TDHC from Calbiochem, La Jolla, CA; secretin from Kabi, Greenwich, CT; and glucagon from Sigma, St. Louis, MO.

Surgical procedure. In the puppies, anesthesia was induced with ketamine (25-50 mg/ $\mathrm{kg}$, intraperitoneal) and pentobarbital 
sodium (5-20 mg/kg, intraperitoneal) injections. Adult dogs were anesthetized with $40 \mathrm{mg} / \mathrm{kg}$ pentobarbital sodium, intravenous. In the puppies, the surgical preparation included cannulation of trachea, two jugular veins, one carotid artery, the common bile duct, and the urinary bladder, and ligation of the cystic duct. Adult dogs were intubated and two femoral veins, one femoral artery, and the common bile duct were cannulated, and the cystic duct and renal pedicles ligated. In all animals, the bile in the gallbladder was aspirated before ligation of the cystic duct. During surgery and throughout the experimental period, body temperature was monitored with a rectal probe and maintained at $37.3 \pm 0.2^{\circ} \mathrm{C}$ by means of heating pads placed under the animal and connected to a temperature controller device (Yellow Springs Instruments, Yellow Springs, $\mathrm{OH}$ ).

Experimental procedure. Immediately after surgery, a 15-min bile collection period was carried out to obtain a bile and plasma sample for background purposes. An intravenous injection of ${ }^{14} \mathrm{C}$-erythritol $(2-10 \mu \mathrm{Ci})$ was then administered followed by a constant infusion $(0.5-3 \mu \mathrm{Ci} / \mathrm{h})$. Spontaneously secreted bile was collected for a 60 -min period, after which the choleretic effects of TC, TDHC, secretin, and glucagon were studied. The experiments were divided in three groups, according to the protocol used. In group I (puppies of $0-42$ days of age, $n=19$ ), we tested the effects of the three substances, namely TDHC, secretin, and glucagon. TDHC was infused at $2 \mu \mathrm{mol} / \mathrm{min} / \mathrm{kg}$ for $45-60 \mathrm{~min}$ (until steady-state choleresis was reached), whereas secretin and glucagon were infused at $10 \mathrm{CU} / \mathrm{kg} / \mathrm{h}$ and $10 \mu \mathrm{g} / \mathrm{kg} / \mathrm{h}$, respectively, for $30-45 \mathrm{~min}$. After the infusion or the bile acid of hormone was terminated, an equilibration period was carried out (45-60 min), after which a second test substance was infused. In 14 puppies of group I, only two substances (TDHC and a hormone, or two hormones) were tested in each dog, and the experimental period was limited to $3-4 \mathrm{~h}$. In five puppies $(2,7$, 14,21 , and 42 days of age) spontaneous bile flow rate declined minimally during the 3 - to 4 -h experimental period, and a third substance was also infused. Since bile flow rate is a critical indicator of hepatic function, and of general condition of health, we reasoned that a prolonged experimental period was warranted in these animals. In group II (four puppies of 0-3 days of age, four of 7-21, and three of 28-42), we tested the effects of TC and secretin. TC was infused at $0.5,1.0$, and $2.0 \mu \mathrm{mol} / \mathrm{min} / \mathrm{kg}$ during three consecutive 60 -min periods, whereas secretin was infused at $10 \mathrm{CU} / \mathrm{kg} / \mathrm{h}$ for $30-45$, as above. These experiments were carried out with a different protocol since one of our initial objectives was to quantitate bile acid dependent and independent bile flow in the developing puppy, as previously described (13). The results obtained from these studies are reported here because some of the data (secretin choleresis) were not included in our previous article, and some (spontaneous bile secretion and TC choleresis) allow a useful comparison with the findings obtained from group I experiments. In group III (four fed and four fasted adult dogs), we studied the effects of TC $(2 \mu \mathrm{mol} / \mathrm{min} / \mathrm{kg}$ for $45-$ $60 \mathrm{~min}$ ), TDHC $(2 \mu \mathrm{mol} / \mathrm{min} / \mathrm{kg}$ for $45-60 \mathrm{~min})$, secretin $(10$ $\mathrm{CU} / \mathrm{kg} / \mathrm{h}$ for $30-45 \mathrm{~min})$, and glucagon $(10 \mu \mathrm{g} / \mathrm{kg} / \mathrm{h}$ for $30-45$ $\mathrm{min})$. Three substances were invariably tested in each adult dog. In selective experiments of group I and III both hormones were infused also at lower and higher rates (see "Results"). In all animals, the order of infusion of TC, TDHC, secretin, and glucagon was randomly chosen. Bile was collected in preweighed vials kept on ice over 15-min intervals. Arterial blood was withdrawn during the first 60 -min bile collection period $(1-2 \mathrm{ml})$ to determine plasma electrolyte levels, and every $15 \mathrm{~min}$ thereafter $(100 \mu \mathrm{l})$ for radioactivity measurement. At the end of the experiment, the animal was sacrificed with an overdose of pentobarbital, the liver removed, and its weight determined.

Analyses. Bile flow rate was determined by the difference between the weights of filled and empty collecting vials. Total bile acids were quantitated by the hydroxysteroid dehydrogenase procedure. Sodium and potassium were determined by flame photometry, chloride with a Selectrode (Radiometer, Copen- hagen), and bicarbonate with a Natelson microgasometer. Bicarbonate concentrations were measured after each plasma and bile collection. Calcium was measured by colorimetry, and the osmolality by freezing-point depression (Osmette, Precision Systems, Sudbury MA). Hepatic water content was estimated by drying tissue specimens to constant weight at $95^{\circ} \mathrm{C}$. Means were compared by the one-way analysis of variance using Prophet, a computer resource sponsored by the Division of Research Resources of the National Institutes of Health. Differences among means were considered to be statistically significant when $p<$ 0.05 .

\section{RESULTS}

Plasma electrolytes. In the puppies, plasma electrolyte levels did not change with age, and were quite similar to those observed in fed or fasted adult dogs. Sodium (140-148 mEq/liter), potassium (4.2-4.8 mEq/liter), chloride (103-112 mEq/liter), and bicarbonate $(22-27 \mathrm{mEq} /$ liter $)$ concentrations were always within the physiological range, and so was plasma osmolality (280-290 mosmol/liter).

Liver weight and $\mathrm{H}_{2} \mathrm{O}$ content. As previously reported (14), the wet liver weight/body weight ratio was virtually the same in puppies of $0-42$ days of age (mean $\pm \mathrm{SD}=4.64 \pm 0.18 \%$ ). In adult dogs, however, the wet liver weight represented $2.19 \pm 0.32$ and $2.33 \pm 0.47 \%$ of body weight in fed and fasted animals, respectively, values significantly lower $(p<0.05)$ than those observed in the puppies. Hepatic $\mathrm{H}_{2} \mathrm{O}$ content was also significantly higher $(p<0.05)$ in puppies of $0-42$ days of age $(75.8 \pm$ $1.6 \%)$ than in fed $(70.6 \pm 1.1 \%)$ or fasted $(71.4 \pm 0.9 \%)$ adult dogs. However, the difference in $\mathrm{H}_{2} \mathrm{O}$ content did not account entirely for the larger liver size of the puppies. In fact, the dried liver weight/body weight ratio in the puppies $(1.12 \pm 0.09 \%)$ was still significantly higher $(p<0.05)$ than that seen in adult dogs $(0.64 \pm 0.06$ and $0.66 \pm 0.07 \%)$. Similar findings have been obtained in other species (1).

Gallbladder bile. The results are reported in Figure 1 and Table 1. Although gallbladder bile volume varied from puppy to puppy, no consistent pattern of volume changes as a function of age could be observed. When expressed per unit of body weight, the volumes in puppies 0-42 days of age were significantly lower than those in fasted adult dogs, but virtually the same as the volumes seen in fed animals. Conversely, the concentrations of

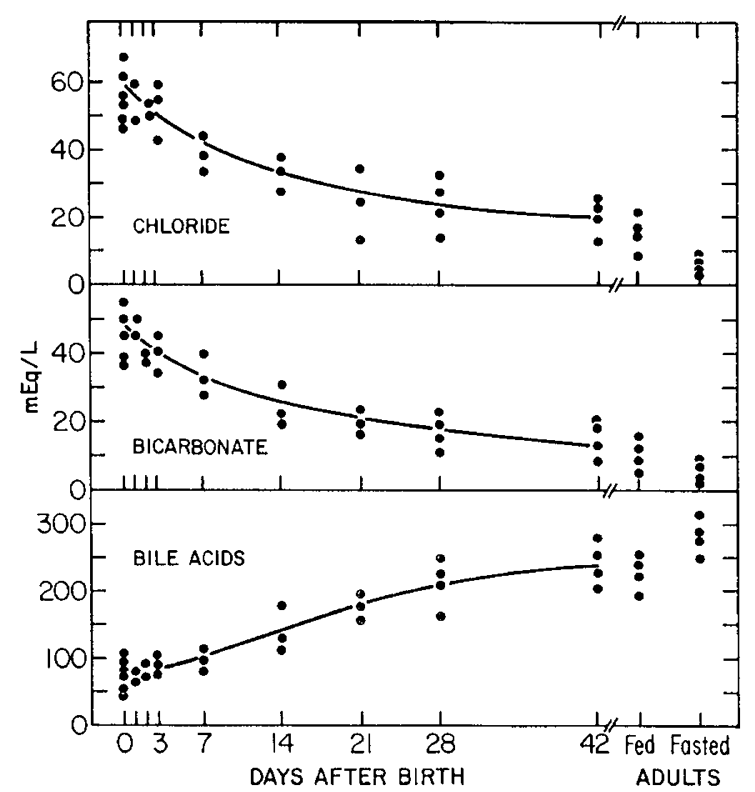

Fig. 1. Concentrations of chloride, bicarbonate, and bile acids in gallbladder bile of puppies of different ages and of fed and fasted adult dogs. 
Table 1. Composition of gallbladder bile in puppies of 0-42 days of age and adult dogs (mean $\pm S D$ )

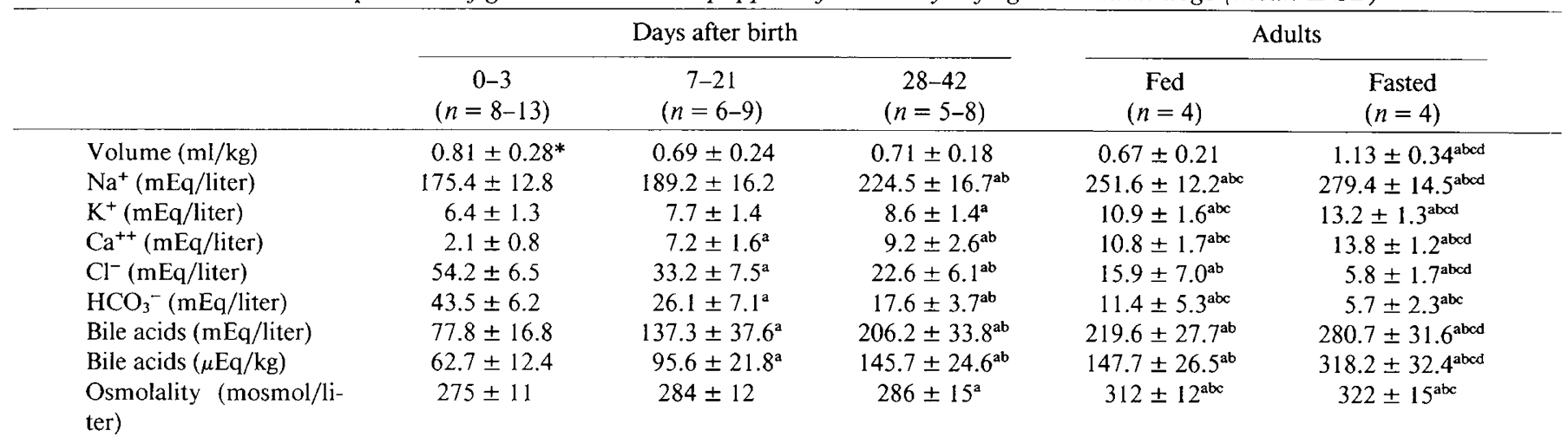

* Significant differences $(p<0.05-0.001)$ were established the one-way analysis of variance: ${ }^{\mathrm{a}}$ compared to 0 - to 3 -day-old puppies; ${ }^{\mathrm{b}}$ compared to 7 - to 21 -day-old -puppies; ${ }^{\mathrm{c}}$ compared to 28 - to 42 -day-old puppies; ${ }^{\mathrm{d}}$ compared to fed adult dogs.

Table 2. Spontaneous bile flow and composition in puppies of 0-42 days of age and adult dogs (mean $\pm S D)^{*}$

\begin{tabular}{|c|c|c|c|c|c|}
\hline & \multicolumn{3}{|c|}{ Days after birth } & \multicolumn{2}{|c|}{ Adults } \\
\hline & $\begin{array}{c}0-3 \\
(n=9-13)\end{array}$ & $\begin{array}{c}7-21 \\
(n=7-9) \\
\end{array}$ & $\begin{array}{c}28-42 \\
(n=8) \\
\end{array}$ & $\begin{array}{c}\text { Fed } \\
(n=4)\end{array}$ & $\begin{array}{c}\text { Fasted } \\
(n=4)\end{array}$ \\
\hline${ }^{14} \mathrm{C}-\mathrm{B} / \mathrm{P}(\mathrm{dpm} / \mathrm{dpm})$ & $1.05 \pm 0.05$ & $1.08 \pm 0.07$ & $1.26 \pm 0.12^{\mathrm{ab}}$ & $1.48 \pm 0.14^{\mathrm{abc}}$ & $1.70 \pm 0.24^{\mathrm{abc}}$ \\
\hline${ }^{14} \mathrm{C}$-Clearance $(\mu \mathrm{l} / \mathrm{min} / \mathrm{g})$ & $0.204 \pm 0.08$ & $0.317 \pm 0.07^{\mathrm{a}}$ & $0.458 \pm 0.08^{\mathrm{ab}}$ & $0.511 \pm 0.11^{\mathrm{ab}}$ & $0.423 \pm 0.08^{\mathrm{ab}}$ \\
\hline $\mathrm{H}_{2} \mathrm{O}$ Reabsorption $(\mu \mathrm{l} / \mathrm{min} / \mathrm{g})$ & $0.008 \pm 0.01$ & $0.023 \pm 0.011^{\mathrm{a}}$ & $0.094 \pm 0.04^{\mathrm{ab}}$ & $0.166 \pm 0.06^{\mathrm{abc}}$ & $0.175 \pm 0.03^{\mathrm{abc}}$ \\
\hline $\mathrm{HCO}_{3}^{-}(\mathrm{mEq} /$ liter $)$ & $22.1 \pm 4.8$ & $23.7 \pm 5.6$ & $26.9 \pm 6.5$ & $38.7 \pm 6.5^{\mathrm{abc}}$ & $31.8 \pm 6.9^{\mathrm{ab}}$ \\
\hline Bile Acids (mEq/liter) & $26.7 \pm 9.3$ & $29.5 \pm 4.9$ & $32.8 \pm 6.4$ & $59.7 \pm 7.4^{\mathrm{abc}}$ & $68.5 \pm 12.2^{\mathrm{abc}}$ \\
\hline Bile Acids (nEq/min/g) & $5.3 \pm 0.7$ & $8.6 \pm 0.8^{\mathrm{a}}$ & $11.9 \pm 1.4^{\mathrm{ab}}$ & $20.6 \pm 3.4^{\mathrm{abc}}$ & $16.7 \pm 3.1^{\mathrm{abc}}$ \\
\hline Osmolality (mosmol/liter) & $286 \pm 11$ & $291 \pm 14$ & $288 \pm 13$ & $300 \pm 12$ & $302 \pm 16$ \\
\hline
\end{tabular}

* Values were obtained during the first 60 -min bile collection period which followed cannulation of the common bile duct. ${ }^{14} \mathrm{C}$ refers to ${ }^{14} \mathrm{C}$ erythritol. $\mathrm{H}_{2} \mathrm{O}$ reabsorption was calculated as: ${ }^{14} \mathrm{C}$-erythritol biliary clearance-bile flow.

abc Significant differences $(p<0.05-0.001)$ were established by the one-way analysis of variance (see legend to Table 1 for details).

electrolytes in gallbladder bile all changed as a function of age. The most striking changes involved sodium, chloride, bicarbonate, and bile acids. Bicarbonate and chloride concentrations declined with age, whereas sodium, potassium, calcium and bile acid concentrations increased. Bile acid content also increased with age, and so did bile osmolality.

Spontaneous bile flow and composition. The results are summarized in Table 2. As previously reported (13), the rate of spontaneous bile flow (first four 15-min collections which followed cannulation of the common bile duct) in the puppies increased as a function of age. In puppies of 28-42 days of age, bile flow rate averaged $0.365 \mu \mathrm{l} / \mathrm{min} / \mathrm{g}$ liver, a value similar to that in fed adult dogs $(0.344 \mu \mathrm{l} / \mathrm{min} / \mathrm{g})$, but significantly higher than that in fasted animals $(0.248 \mu \mathrm{l} / \mathrm{min} / \mathrm{g})$. The excretion rate of endogenous bile acids also increased with age in the puppies. Unlike that in bile flow, however, the age-related increase in bile acid excretion was less pronounced, and the values observed in 28- to 42-day-old puppies were only $50-65 \%$ of those seen in adult dogs. Steady-state ${ }^{14} \mathrm{C}$-erythritol $\mathrm{B} / \mathrm{P}$ also increased with age, and the differences in solute biliary clearance, which has been suggested to estimate canalicular bile flow $(15,16)$, were even more accentuated than those in bile flow. When ductular water reabsorption was calculated $\left({ }^{14} \mathrm{C}\right.$-erythritol clearance-bile flow), an age-related increase was observed. In 0- to 3-day-old puppies, ductular bile water reabsorption was virtually absent. As in the gallbladder, the concentration of chloride in spontaneously secreted hepatic bile decreased with age, whereas that of sodium increased. Bicarbonate levels were the same in puppies of 0-42 days of age, although the values seen in adult dogs were significantly higher than those observed in the puppies.

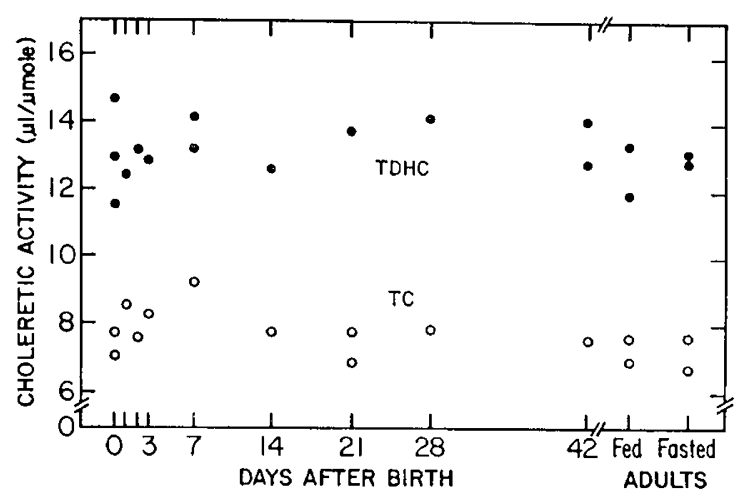

Fig. 2. Choleretic activity of TC and TDHC in puppies of different ages, and in fed and fasted adult dogs. In the puppies, TDHC was infused at $2 \mu \mathrm{mol} / \mathrm{min} / \mathrm{kg}$ (group I experiments), whereas TC was infused at 0.5 , 1 , and $2 \mu \mathrm{mol} / \mathrm{min} / \mathrm{kg}$ (group II). However, the data reported herein are those obtained during administration of $2 \mu \mathrm{mol} / \mathrm{min} / \mathrm{kg}$ TC. Values shown were obtained at steady-state bile flow.

Bile acid choleresis. Infusion of TDHC at $2 \mu \mathrm{mol} / \mathrm{min} / \mathrm{kg}$ produced a similar choleretic effect in all animals, regardless of their age. The biliary excretion of total bile acids during infusion of TDHC was also the same in the puppies and adult dogs and accounted for $70-95 \%$ of the administered dose. The choleretic activity of TDHC averaged $13.3 \mu \mathrm{l} / \mu \mathrm{mol}$ of total bile acids excreted in puppies of $0-42$ days of age, and $12.7 \mu \mathrm{l} / \mu \mathrm{mol}$ in adult dogs (Fig. 2). As previously reported (13), TC also produced 
a similar effect in puppies of 0-42 days of age and adult dogs when infused at doses ranging from $0.5-2.0 \mu \mathrm{mol} / \mathrm{min} / \mathrm{kg}$. At 2 $\mu \mathrm{mol} / \mathrm{min} / \mathrm{kg}$, however, the choleretic activity of TC was lower than that of TDHC, and averaged $7.8 \mu \mathrm{l} / \mu \mathrm{mol}$ in the puppies and $7.2 \mu \mathrm{l} / \mu \mathrm{mol}$ in adult dogs (Fig. 2). As observed with TDHC, the biliary excretion of total bile acids during infusion of $2 \mu \mathrm{mol} /$ $\mathrm{min} / \mu \mathrm{kg}$ TC was the same in all animals, and accounted for 70$95 \%$ of the administered dose.

Hormone choleresis. The effects of secretin and glucagon on bile flow in puppies of different age and adult dogs are illustrated in Figures 3 and 4 . At $10 \mathrm{CU} / \mathrm{kg} / \mathrm{h}$ and $10 \mu \mathrm{g} / \mathrm{kg} / \mathrm{h}$, respectively, secretin and glucagon either failed to stimulate bile flow or produced a minimal choleretic effect when infused into 0 - to 3day-old puppies. As the animal's age increased, the choleretic effects of both hormones were more pronounced and, in puppies of 28-42 days of age, bile flow rate increased by an average of 0.172 and $0.104 \mu \mathrm{l} / \mathrm{min} / \mathrm{g}$ liver during secretin and glucagon administration, respectively. However, the increases in flow produced by $10 \mathrm{CU} / \mathrm{kg} / \mathrm{h}$ secretin and $10 \mu / \mathrm{kg} / \mathrm{h}$ glucagon in fed $(0.417$ and $0.243 \mu \mathrm{l} / \mathrm{min} / \mathrm{g}$ liver, respectively) and fasted $(0.512$ and $0.297 \mu \mathrm{l} / \mathrm{min} / \mathrm{g}$ ) adult dogs were from two to four times greater than those seen in puppies of 28-42 days of age. As shown in Figure 4, similar age-related differences in the effects of both hormones were observed when the increase in bile flow was expressed as a percentage of the precholeretic (control) rate. With no surprise, bicarbonate concentration in bile remained essentially unchanged during glucagon choleresis, but increased significantly when bile flow was stimulated by secretin. The increase in biliary bicarbonate concentration produced by secretin was related to animal's age in a manner similar to that observed for the stimulation of bile flow (Fig. 4).

The age dependency of the choleretic effect of secretin and glucagon was not related to the doses employed. In two puppies of 0 and 1 day of age (group I), which were not responsive to the doses described above, no effect on bile flow was observed when 1 and $20 \mathrm{CU} / \mathrm{kg} / \mathrm{h}$ secretin, and 1 and $20 \mu \mathrm{g} / \mathrm{kg} / \mathrm{h}$ glucagon were infused. Conversely, in five puppies of 7-42 days of age (group I) and adult dogs (one fed and one fasted), the increase in bile flow produced 1 and $10 \mathrm{CU} / \mathrm{kg} / \mathrm{h}$ secretin, and 1 and $10 \mu \mathrm{g} / \mathrm{kg} /$ h glucagon, was always proportional to the dose infused.

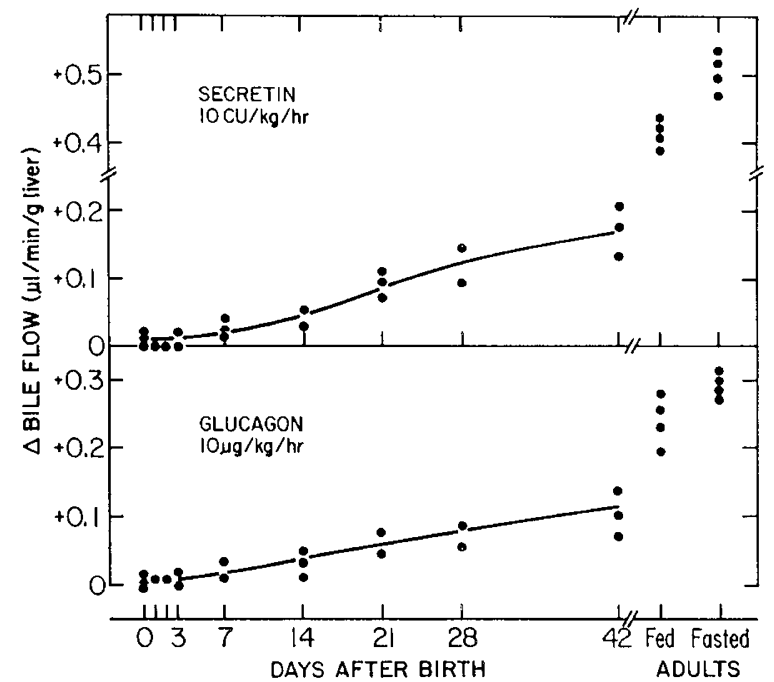

Fig. 3. Increase in bile flow rate produced by secretin and glucagon in puppies of different ages and in fed and fasted adult dogs. Values were obtained by substracting the precholeretic (control) rate from the highest rate (steady-state) observed during hormone infusion. For the puppies, the glucagon data were all obtained from group I experiments, whereas the secretin data were obtained both from group I (11 puppies) and group II (nine puppies). See "Methods" for more details.

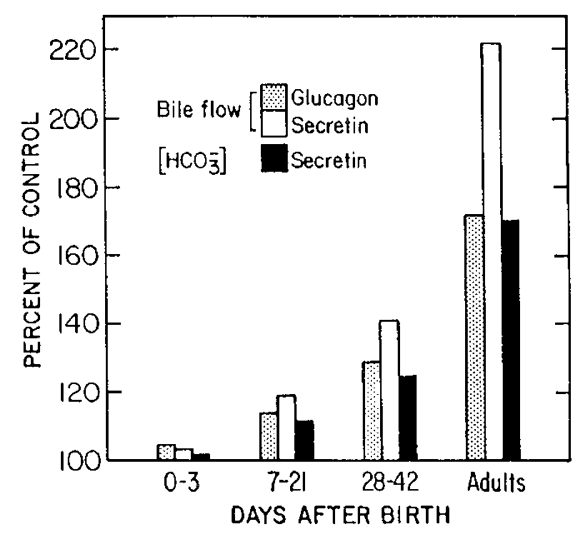

Fig. 4. Effects of secretin $(10 \mathrm{CU} / \mathrm{kg} / \mathrm{h})$ and glucagon $(10 \mu \mathrm{g} / \mathrm{kg} / \mathrm{h})$ on bile flow, and of secretin on biliary bicarbonate concentrations in puppies of different ages and in fed adult dogs. Hormone-stimulated bile flow and bicarbonate concentrations are expressed as percentages of control values.

\section{DISCUSSION}

In the present studies, we have shown age-related differences in 1) electrolyte concentrations in gallbladder and hepatic bile, 2) spontaneous hepatic bile secretion, and 3) hormone-induced choleresis in puppies of $0-42$ days of age. In gallbladder bile, the concentrations of bicarbonate and chloride declined with age, whereas those of sodium, potassium, calcium, and bile acids increased. The rate of spontaneous bile flow also increased as a function of puppies' age, as did ${ }^{14} \mathrm{C}$-erythritol $\mathrm{B} / \mathrm{P}$ and the biliary concentration of sodium. As in the gallbladder, chloride concentration in hepatic bile decreased with age, although the concentration of bicarbonate remained virtually unchanged. Finally, while administration of TC and TDHC resulted in a similar choleretic effect in all puppies and adult dogs, infusion of secretin and glucagon at doses producing extensive choleresis in adult animals, resulted in no or minimal stimulation of bile flow in 0 to 3-day-old puppies. The ability of both hormones to induce bile flow increased with puppies' age, and by the 4-6th wk of postnatal life, their choleretic effect was $30-45 \%$ of that observed in adult dogs. These findings, together with those previously reported (13), suggest that, in the dog, both secretory and reabsorptive processes of the biliary system are immature at birth, and develop during postnatal life.

Gallbladder bile. The composition of gallbladder bile is determined by the composition of hepatic bile, gallbladder retention time, and the rate of gallbladder water and solute reabsorption and/or secretion. The age-related increase in gallbladder bile acid concentration and content observed in these studies is most likely secondary to the age-related increase in the biliary excretion of endogenous bile acids which, in turn, reflects the postnatal expansion of bile acid pool size (2-4). However, the age-related changes in gallbladder electrolyte concentrations cannot be accounted for by the changes in electrolyte concentrations in hepatic bile, since the latter were very small and involved only the concentrations of sodium and chloride. Thus, differences in retention time and/or in reabsorptive-secretory activity of the gallbladder must primarily underlie those in electrolyte concentrations. Since eating habits and hormone milieu change during postnatal life, it is conceivable that gallbladder emptying time varied as well in our puppies of different age. However, the present results support the conclusion that age-related differences in gallbladder reabsorptive and/or secretory activities are primarily, if not exclusively, responsible for those in electrolyte concentrations. First, gallbladder bile in fed adult dogs, in which the retention time was clearly shorter than that in fasted animals, was more diluted, but the electrolyte concentrations were signif- 
icantly different from those seen in 0 - to 3-and 7- to 21-day-old puppies. Second, gallbladder bile volume was virtually the same in all puppies, regardless of their age. Were a discrete age-related change in retention time to occur, gallbladder bile volume should have changed with age as well. Finally and more importantly, in puppies of 0-3 days of age bicarbonate concentrations in gallbladder bile were much higher than those in hepatic bile. Such a concentration gradient cannot be explained by postulating agerelated differences in retention time, but only in gallbladder reabsorptive and/or secretory activities. Gallbladder water reabsorption has convincingly been demonstrated to be secondary to a sodium-coupled chloride transport (17). Moreover, since bicarbonate enhances the water reabsorption rate (18), a parallel counter-transport of sodium-hydrogen and chloride-bicarbonate has been proposed $(18,19)$. Accordingly, the age-related decrease in chloride and bicarbonate concentrations observed in these studies may reflect a postnatal development of such a transport mechanism. On the other hand, gallbladder mucosa can secrete water and electrolytes into the lumen, and hormones like secretin and vasoactive intestinal peptide not only can inhibit the reabsorption, they can reverse it into a net secretion (20-23). Since in the early stages of extrauterine life plasma concentrations of secretin and other hormones may exceed adult levels (24-26), the high concentrations of bicarbonate and chloride in the puppies' gallbladder bile could be due to a hormone-induced inhibition of reabsorption or hormone-induced stimulation of anion secretion. The present results do not allow a rigorous distinction among these mechanisms. However, since bicarbonate concentrations in the gallbladder bile of 0- to 3-day-old puppies were twice as high as those in plasma and hepatic bile, a neonatal inversion of the sodium-hydrogen and chloride-bicarbonate counter-transport mechanism, whatever the cause might be, appears to be a more appealing possibility.

Spontaneous bile formation. We have previously demonstrated that, in the puppy, spontaneous bile flow and ${ }^{14} \mathrm{C}$-erythritol $\mathrm{B} / \mathrm{P}$ and biliary clearance increase as a function of age (13). We suggested that bile acid independent and dependent bile flow and ductular bile water reabsorption are all deficient in the newborn dog and develop during postnatal life. The results reported herein, which include data from some of the previous experiments (13) and from 19 new puppies and four fed adult dogs, are fully consistent with those already published. However, since ${ }^{14} \mathrm{C}$-erythritol biliary clearance may not accurately measure canalicular bile flow $(27,28)$, these conclusions must be made with considerable caution. Indeed, it is quite likely that, as in other species $(29,30),{ }^{14} \mathrm{C}$-erythritol permeates the biliary ductules/ducts in the dog as well, and the permeability of these distal structures to such a solute may be greater in the newborn puppy than in the adult animal. Nevertheless, chloride concentration in spontaneously secreted bile declined with age, and an inverse relationship between ${ }^{14} \mathrm{C}$-erythritol $\mathrm{B} / \mathrm{P}$ and biliary chloride concentration has been demonstrated in the $\operatorname{dog}(31)$, and construed to suggest a distal water reabsorption secondary to a sodiumcoupled chloride transport, as in the gallbladder. Thus, since these studies strongly suggest that gallbladder water reabsorption is deficient in the newborn dog, it is not inconceivable that a similar immaturity exists also at the level of the biliary epithelium.

Bile acid choleresis. Smallwood et al. (3) first demonstrated that the fetal dog liver, 1 wk before term, excretes exogenously administered bile acids with remarkable efficiency. We have previously shown that the biliary excretion and choleretic effect of TC in the newborn puppy are the same as those in the adult dog (13). The results of the present studies now indicate that the newborn dog's liver handles an exogenous load of TDHC, a synthetic triketo derivative, as well as it handles that of $\mathrm{TC}$, a physiological bile acid in this species. As observed during TC administration, in fact, the biliary excretion of total bile acids following infusion of TDHC accounted for $70-95 \%$ of the given dose in all animals, regardless of their age. Since bile acids were quantitated by the hydroxysteroid dehydrogenase procedure, such a finding indicates a quantitative reduction of TDHC to 3hydroxy derivatives, thus supporting the conclusion that the metabolic events underlying TDHC metabolism are developed in the newborn dog's liver. In keeping with previous observations (32), the increase in bile flow produced by TDHC was, for similar rates of total bile acid excretion, greater than that induced by TC. The reason for this difference is not entirely clear, but the non-micelle forming property of TDHC may be an important determinant of its greater choleretic activity $(32,33)$.

Hormone choleresis. Although the ontogeny of hormone-mediated events has been studied extensively, the choleretic effects of secretin and glucagon have not been examined in fetuses or newborn organisms. The results of the present studies have demonstrated that both hormones produce a minimal, or no stimulation of bile flow in 0- to 3-day-old puppies, and that their ability to induce choleresis increases with animal's age. Since the present experiments, unlike those carried out in target tissues, were conducted in the intact animal, the precise mechanism for the age-related differences in the choleretic effects of both hormones remains to be established. In puppies of $0-4$ days of age, plasma levels of glucagon are from three to four times higher than those in the adult dog (24). Although secretin plasma levels have not been measured in newborn puppies, data from neonatal swines (26) and human infants (25) have demonstrated a similar age-related change. It is thus possible that spontaneous bile secretion in the newborn dog is maximally stimulated by the high plasma levels of secretin and glucagon, so that administration of exogenous doses of these hormones no longer results in a choleretic response. At least with respect to glucagon, however, plasma hormone levels in puppies of 12 days of age or older are similar to those in adult animals (24), yet the choleresis produced in our puppies of 14-42 days of age was far lower than that seen in adult dogs. Thus, such a possibility can explain only in part the present results. Alternatively, the age-related differences in secretin and glucagon cholereses may reflect changes in sensitivity of the hepatic receptors for these hormones and/or in the postreceptor events. Although the mechanisms by which secretin and glucagon stimulate bile flow are not known, hormone binding to cell plasma membrane receptors and activation of the postreceptor complex clearly precede choleretic response. A neonatal immaturity of the hepatic glucagon receptor has been demonstrated in several species (34-36), and the adenylate cyclase system, which is most likely involved in the cascade of events leading to hormone stimulation of bile flow, may develop during postnatal life $(37,38)$. Therefore, the age-related increase in the choleretic response to secretin and glucagon administration observed in our puppies may reflect maturation of the hepatic receptors for these hormones and/or of the postreceptor events leading to stimulation of choleresis.

\section{CONCLUSIONS}

The present studies have demonstrated that in 0- to 42-dayold puppies the electrolyte concentrations in gallbladder bile and hepatic bile, spontaneous bile flow, and the choleretic response to secretin and glucagon administration change as a function of age. These findings are construed to suggest that gallbladder and ductular bile water reabsorption, canalicular secretion, and hormone-induced choleresis are all deficient in the newborn dog and develop during postnatal life. The revelance of these findings to bile secretory physiology in the newborn infant is not known. However, bile secretion and its control in the dog are not too different from those in the human being, and several lines of evidence suggest that bile secretory function is immature in the newborn baby $(4,5,7)$. Thus, the results from these animal experiments may be important in neonatology, particularly in the clinical management of physiological cholestasis, and of 
cholestatic liver disease associated with parenteral feeding that strikes a large number of newborn infants.

Acknowledgments. The author thanks Mary Jane T. Jones for her skillful technical assistance and Mary Barrett for her preparation of this manuscript. Portions of this study were presented at the Society for Pediatric Research Meeting, Washington DC May 6-10, 1985, and published in abstract form (Pediatric Research 19:234A, 1985).

\section{REFERENCES}

1. Stave U 1978 Liver enzymes. In: Stave U (ed) Perinatal Physiology. Plenum, New York, pp 499-521

2. Little JM, Richey JE, Van Thiel DH, Lester R 1979 Taurocholate pool size and distribution in the fetal rat. J Clin Invest 63:1042-1049

3. Smallwood RA, Lester R, Piasecki GJ, Klein PD, Grego R, Jackson BT 1972 Fetal bile salt metabolism. II. Hepatic excretion of endogenous bile salt and of a taurocholate load. J Clin Invest 51:1388-1397

4. Watkins JB, Ingall D, Szczepanik P, Klein PD, Lester R 1973 Bile salt metabolism in the newborn, measurement of pool size and synthesis by stable isotope technique. N Engl J Med 288:431-434

5. Watkins JB, Szczepanik P, Gould J, Klein P, Lester R 1975 Bile salt metabolism in the human premature infant. Preliminary observations of pool size and synthesis rate following prenatal administration of dexamethasone and phenobarbital. Gastroenterology 69:706-713

6. Belknap WM, Balistreri WF, Suchy FJ, Miller PC 1981 Physiologic cholestasis. II. Serum bile acid levels reflect the development of the enterohepatic circulation in rats. Hepatology 1:613-616

7. Suchy FJ, Balistreri WF, Heubi JE, Searcy JE, Levin RS 1981 Physiologic cholestasis: elevation of the primary serum bile acid concentrations in normal infants. Gastroenterology 80:1037-1041

8. Heubi JE, Fondacaro JD 1983 Postnatal development of intestinal bile salt transport in the guinea pig. Am J Physiol 243:G189-G194

9. Lester R, Smallwood RA, Little JM, Brown AS, Piasecki GJ, Jackson BT 1977 Fetal bile salt metabolism. The intestinal absorption of bile salts. J Clin Invest 59:1009-1016

10. Little JM, Lester R 1980 Ontogenesis of intestinal bile salt absorption in the neonatal rat. Am J Physiol 239:G319-G323

11. Benjamin DR 1981 Hepatobiliary dysfunction in infants and children associated with long-term total parenteral nutrition. A clinico-pathologic study. Am J Clin Pathol 76:276-283

12. Postuma R, Trevenen CL 1979 Liver diseases in infants receiving total parenteral nutrition. Pediatrics 63:110-115

13. Tavoloni N, Jones MJT, Berk PD 1985 Postnatal development of bile secretory physiology in the dog. J Pediatr Gastroenterol Nutr 4:256-267

14. Tavoloni $N 1985$ Postnatal changes in hepatic microsomal enzyme activities in the puppy. Biol Neonate 47:305-316

15. Forker EL 1967 Two sites of bile formation as determined by mannitol and erythritol clearance in the guinea pig. J Clin Invest 46:1189-1195

16. Wheeler HD, Ross ED, Bradley SE 1968 Canalicular bile production in dogs. Am J Physiol 214:866-874
17. Frizzell RA, Dugas M, Schultz SG 1975 Sodium chloride transport by rabbit gallbladder: direct evidence for a coupled $\mathrm{NaCl}$ influx process. J Gen Physiol 65:769-795

18. Heintze K, Petersen KU, Wood JR 1981 Effects of bicarbonate on fluid and electrolyte transport by guinea pig and rabbit gallbladder: stimulation of absorption. J Membr Biol 62:175-182

19. Petersen KU, Wood JR, Schultze SG, Heintze K 1981 Stimulation of gallbladder fluid and electrolyte absorption by butyrate. J Membr Biol 62:183-194

20. Jansson R, Steen G, Svanvik J 1978 A comparison of glucagon, gastric inhibitory peptide and secretin on gallbladder function, formation of bile, and pancreatic secretion in the cat. Scand J Gastroenterol 13:919-925

21. Jansson R, Steen G, Svanvik J 1979 Effects of intravenous vasoactive intestinal peptide on gallbladder function in the cat. Gastroenterology 75:47-50

22. Jansson R, Svanvik J 1977 Effects of intravenous secretin and cholecystokinin on gallbladder net water absorption and motility in the cat. Gastroenterology 72:639-643

23. Stewart CP, Goetz $\mathrm{R}$, Heintze $\mathrm{K} 1982$ Electrogenic $\mathrm{HCO}_{3}$ secretion by guinea pig gallbladder. In: Case RM, Garner A, Turnberg LA, Young JA (eds) Electrolyte and water transport across gastrointestinal epithelia. Raven Press, New York, pp 115-122

24. Hetenyi G, Kovacevic N, Hall SE, Vranic M 1976 Plasma glucagon in pups, decreased by fasting, unaffected by somatostatin or hypoglycemia. Am J Physiol 231:1377-1382

25. Lucas A, Adrian TE, Bloom SR, Aynsley-Green A 1980 Plasma secretin in neonates. Acta Pediatr Scand 69:205-210

26. Moazam F, Rodgers BM, Wheeldom S, Kolts BE 1982 Secretin levels in plasma and tissue of the neonatal swine. Biol Neonate 42:1-7

27. Barnhart JL, Combes B 1978 Erythritol and mannitol clearance with taurocholate and secretin-induced choleresis. Am J Physiol 234:E146-E156

28. Tavoloni N 1984 Permeation patterns of polar nonelectrolytes across the guinea pig biliary tree. Am J Physiol 247:G527-G536

29. Smith ND, Boyer JL 1982 Permeability characteristics of bile duct in the rat. Am J Physiol 242:G52-G57

30. Tavoloni N, Wyssbrod HR, Jones MJT 1985 Permeability characteristics of the guinea pig biliary apparatus. Gastroenterology 88:1700A(abstr)

31. Tavoloni $N 1985$ Role of ductular bile water reabsorption in canine bile secretion. J Lab Clin Med 106:154-161

32. O'Maille ERL 1979 The influence of micelle formation on bile salt secretion. J Physiol (Lond) 302:107-120

33. Tavoloni N, Reed JS, Boyer JL 1978 Hemodynamic effects on determinants of bile secretion in isolated rat liver. Am J Physiol 234:E584-E592

34. Ganguli S, Sinha M, Sperling MA 1984 Ontogeny of insulin and glucagon receptors and the adenylate cyclase system in guinea pig liver. Pediatr Res 18:558-565

35. Ganguli S, Sinha MK, Sterman B, Harris P, Sperling MA 1983 Ontogeny of hepatic insulin and glucagon receptors and adenylate cyclase in rabbit. Am J Physiol 244:E624-E631

36. Vinicor F, Higdon G, Clark JF, Clark CM 1976 Development of glucagon sensitivity in the neonatal rat liver. $J$ Clin Invest 58:571-578

37. Kohrman AF 1973 Patterns of development of adenyl cyclase activity and norepinephrine responsiveness in the rat. Pediatr Res 7:575-581

38. Novak E, Drummond GI, Skasa J, Hahn P 1972 Developmental changes in cyclic AMP, protein kinase, phosphorylase kinase, and phosphorylase in liver, heart and skeletal muscle of the rat. Arch Biochem Biophys 150:511518 